\title{
Holistic Healing Framework: Impact of the Physical Surrounding Design on Patient Healing and Wellbeing
}

\author{
Moamer M. Gashoot \\ Faculty of Science \& Technology, Bournemouth University, Bournemouth, UK \\ Email:m.gashoot@live.co.uk
}

How to cite this paper: Gashoot, M. M. (2022). Holistic Healing Framework: Impact of the Physical Surrounding Design on Patient Healing and Wellbeing. Art and Design Review, 10, 18-28.

https://doi.org/10.4236/adr.2022.101002

Received: October 19, 2021

Accepted: December 19, 2021

Published: December 22, 2021

Copyright $\odot 2022$ by author(s) and Scientific Research Publishing Inc. This work is licensed under the Creative Commons Attribution International License (CC BY 4.0).

http://creativecommons.org/licenses/by/4.0/

\begin{abstract}
With advances in healthcare design settings and technology, previously established frameworks warrant to be revisited. A new framework based on the principles of holistic healing that integrates design theories and incorporates significant interior design components that help designers create healing spaces, through better understanding of user perception and preference of interior design elements is discussed. The holistic healing framework proposed is aimed at achieving satisfaction for single-occupancy room users with their hospital rooms. This framework appears to be particularly valuable in studying and understanding the physical setting and individual interactions within the environmental behaviour and how people perceive their surroundings. The onus is on designers to introduce design and décor to meet hospital room user requirements and showcase designer skills. Addressing a hospital room user's satisfaction with healthcare facilities is only possible if these requirements are clearly documented and environmental behavior theories are fully understood.
\end{abstract}

\section{Keywords}

Healing Environment, Holistic Healing, Patient, Healthcare Design, Behaviour

\section{Introduction}

Health care professionals and designers believe that aesthetically-pleasing décor and art in healthcare environments evoke emotional responses and are therefore important to patients' well-being and their satisfaction with the healthcare provided (Nasar, 1988; Nasar, 1994; Biley, 1996; Palmer \& Nash, 1997; Moore, 2000; 
Ulrich, 2001).

The layout of the room, wall colors, artwork, and furnishing enhance patient feelings of comfort and security, and maintain a positive frame of mind, that allows patients to remain positively engaged in a single occupancy hospital room during hospitalization (Fottler et al., 2000) Physical settings may influence users' satisfaction with the environment (Allderson, Green, \& Niggins, 2004; Bitner, 1992). A user's perception of the environment is affected by sociological needs, psychological state, and individual differences. Similarly, the interior of a single occupancy room also affects and influences human behaviour. Among the social needs, individual privacy, personal interaction levels within the environment, and territoriality affect individual behaviour. For example, single occupancy offers privacy, and screens offer privacy in double rooms. Individual territoriality involves the exclusive control of a space by an individual who may consider the hospital room as personal territory and therefore personalizes it to express themselves and form emotional ties with the environment. There are three distinct distances at which interpersonal transactions normally take place intimate, personal, and social that should be considered by the designer who should apply ergonomic principles when planning the hospital room.

Intimate space: area immediately surrounding the individual's body and is the most private which involves both physical and emotional response.

Interior personal space: area within which users allows only select friends, or family with whom personal conversation is mandatory.

Social space: area within which the users expect to make purely social contacts on a temporary basis with others.

Previous theoretical models devised by environmental psychologist (Mehrabian \& Russell, 1974; Russell \& Pratt, 1980), and the "servicescape" framework by Mary Jo Bitner (1992) have failed to address advances in design and technology. The aim of this article is to present the development of a new framework that can be used to achieve holistic health in a hospital setting (Figure 1). The proposed framework is supported by empirical research findings and available knowledge that fill gaps in Mary Jo Bitner's framework (1992), developed by M Gashoot (2021). A theoretical framework of holistic healing, with contributions from physical dimensions and setting, interior conditions, internal responses, individual behaviours, design configuration, and desired behaviour in relation to single occupancy in healthcare setting, is discussed (Gashoot, 2021).

\section{Conceptual Holistic Healing Framework}

An individual's perception of his/her physical environment evokes emotions, cognitive and physiological responses, which affect behavior (Mika, 2008). In the context of a single occupancy hospital room, the emotional responses that are elicited influence an individual's behaviour (Bitner, 1992). The emotional 


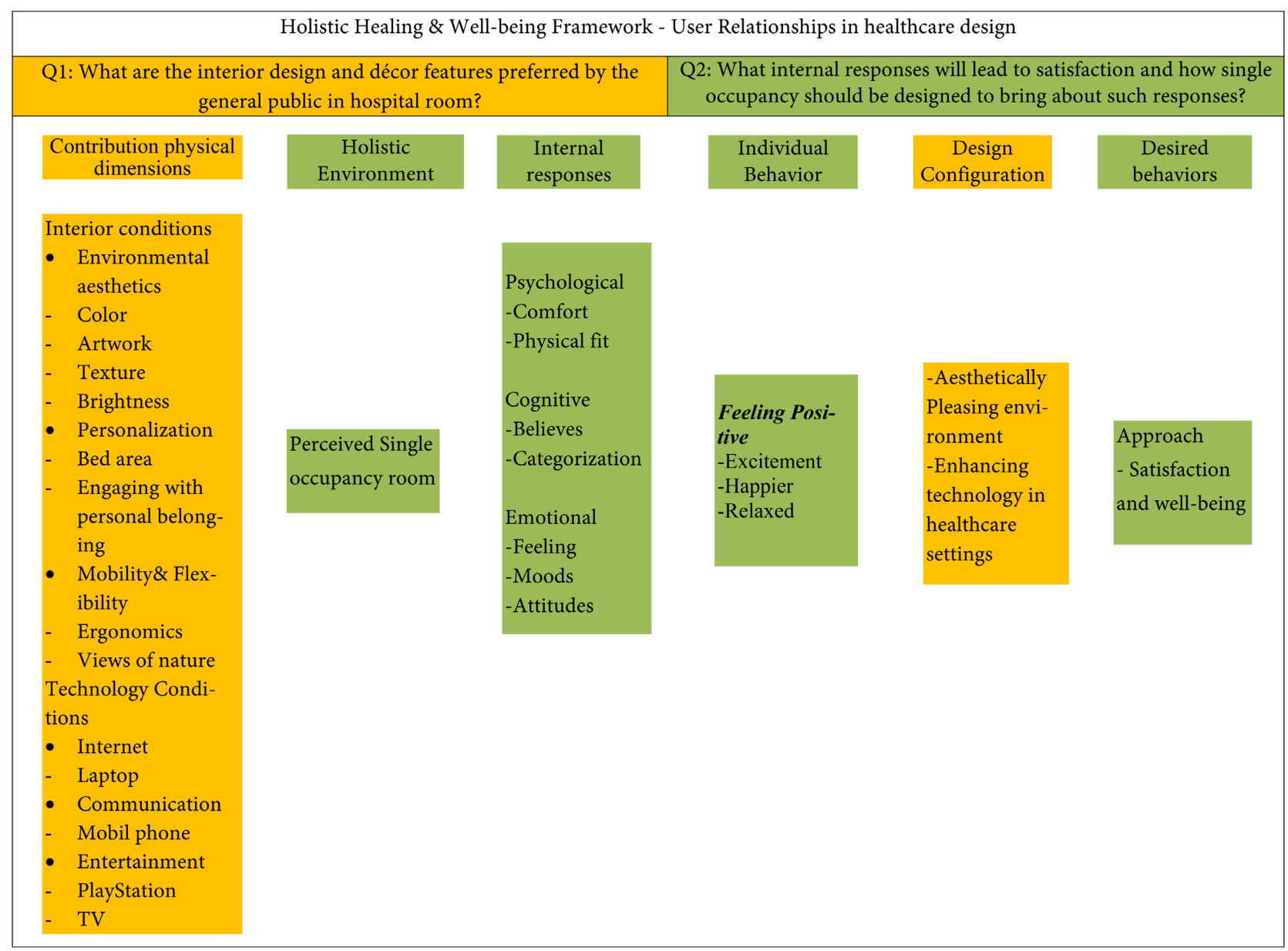

Figure 1. Holistic healing \& well-being framework-user relationships in healthcare design.

response can be considered to be a pleasure or an arousal, both of which drives positive behaviour (Mika, 2008). Pleasure can be derived from an aesthetically pleasing single occupancy room, whereas arousal arises from a poorly designed room. Therefore, hospital design and décor professionals and healthcare providers need to promote patient healing and satisfaction by influencing positive emotional responses and behavior.

Cognition is the mental processing of sensory information (Mika, 2008). People generally seek a point of similarity between observation and experience. Therefore, increased familiarity of a hospital room can reduce confusion and unhappiness among patients (Fottler et al., 2000). The patient will make a cognitive association with either past healing or their own home design that affect their preferences for the choice of room aesthetics.

Just as we react physiologically to environmental properties such as air quality, sound, and temperature and also to any associated discomforts (Mika, 2008), a hospitalized patient responds physiologically to the type of furniture, material, equipment, finish and wall color and if satisfied, will lead to positive emotions "happy", "relaxed", and "excitement". Therefore, during the planning phase for designing hospital rooms, an interior designer should consider several factors 
that deal with physiological responses including functionality and ergonomics. Every aspect of hospital room design needs to be carefully assessed in term of its compatibility with human body, which when met, will satisfy the patient.

Human behavior is influenced by the physical setting (Bitner, 1992) and human perception is affected by mood, personality and experience (Mika, 2008). Thus, individual behavior is a challenge for the healthcare provider and the designer, who must accommodate to these challenges. Mary Jo Bitner (1992) emphasized the influence of interior elements on user behaviour, who responds with either satisfaction or avoidance. A user of a single occupancy room may respond either with satisfaction to light cool wall color and art depicting nature, or avoidance to warm (red, orange, and yellow) wall color that can affect mood.

Environment comfort, which can be physical, functional, or psychological, is achieved when the patient is satisfied with the surroundings. Physical comfort, important for user satisfaction, includes basic human needs such as hygiene and safety, as well as the layout of furniture and medical equipment, which can be achieved by applying the building code and standards. Functional comfort is linked to the ergonomics of the room and the support obtained. Psychological comfort through personalization help in adaption to the hospital room, provides satisfaction, promotes emotional attachment, enhances aesthetics, and encourages creativity. Thus, patient comfort is affected by the designer's choice and should be therefore reflected in the decision-making processes.

\subsection{Visual Attributes of the Framework}

Though Mary Jo Bitner (1992) divided the physical dimensions into architecture, ambient and interior conditions, the framework failed to address design configuration as an important factor that enhances the user's environment. Ambient conditions refer to characteristics of the interior environment which affects the five senses and within a single occupancy room, user satisfaction is vastly improved by its ambience, which includes lighting, music, smells, and scents. The interior conditions comprise the room's layout and functionality refers to equipment and its arrangement, size and the shape of furniture (Bitner, 1992).

Architecture condition refers to structural features that are more or less permanent. The designer should consider factors that provide positive interaction with the environment.

Design configuration is linked to aesthetics and technology in healthcare setting and thus, is very important to achieve desired behavior. The interior designer should fully comprehend the universal concept of aesthetics, and design concepts goes beyond the functionality of the space, and should embrace human senses to achieve user satisfaction by positively influencing mood and behavior (Gashoot, 2021). Thus, psychological and emotional effects can be achieved through the use of the preferred interior element that offer a wide variety of finishes that create interest, shadows, and visual variety within the hospital room. Understanding physical stimuli in hospital rooms will allow designers to create a people-preferred environment to meet satisfaction. 


\subsection{Color as an Aesthetic Tool}

The use of color for health, architecture, and commercial purposes has gained considerable interest over several decades. In support of color as an environmental aesthetic healing tool, Stouffer (Stouffer, 2001) stated the need to shift the argument from fashion and aesthetics into a discipline with valid measurable results confirming the effect the built environment has on a patient's outcome in order for the concept to be taken seriously. Color, in particular bright cool colors (green, blue, or white), can create illusions that enhances the aesthetics in the hospital room to make patients happier, excited and more welcome compared to red, yellow, and orange. Response to color is initiated from a brain impulse, followed afterwards by an emotion red arouses and blue signifies relaxation. Therefore, cool wall colors, such as blue or green lead patients into a restful state. Since the psychological and physiological well-being of patients is extremely important for healing, it is vital for the interior designer to re-consider the type of wall color in the environment that supports patients. Birren (1979) discussed the importance of cool colors for hospitalized patients, long-term patients and those in need of long periods of rest time, and those in waiting rooms to help foster a calming effect on anxious families. Warm colors are recommended for convalescing patients on the way to recovery and maternity patients in need of physical relaxation, and low lighting for emergency rooms where patients wait for examinations or tests. Yellow-green colors should be avoided because reflections from these colors cause the skin to look sallow and unhealthy with an uncomplimentary purple after-image. Nevertheless, color contributes aesthetically to patient welfare. While warm colors bring the object closer to the eye, cool colors recede. Whites and yellows stand apart from other colors. Tall ceilings can be visually lowered with warm tones. Long hallways can be shortened with warms colors at the end. Rooms can become more spacious with cool and muted colors, which have also been established to induce relaxation in a well-designed environment (Birren, 1979).

Regarding the importance of interior design choice, Webster and Johnson (1999) said, "designers have to consider what is important for patients and supportive of their satisfaction, and the difference in their culture context. The understanding of these issues is essential as a foundation for design planning." The emphasis of these statements is that designers should use bright, rather than warm color, for design changes, which reflects the need for new ideas on addressing the choice of wall color in hospital rooms, so as to humanize the single occupancy design to promote fast healing (Alvarez, 2004). Poorly designed single occupancy rooms in hospitals with inappropriate décor further compound an already uncomfortable environment (Dijkstra et al., 2008). Particularly within healing spaces, the choice of wall color, which influences behavior and lead to positive state of mind, is influenced by ethnicity and culture. Therefore, color contrast in the hospital room is a possible room improvement, which should be considered by designers for future design and designers are responsible for the color that enhances patient satisfaction and promotes rapid healing. 


\subsection{Art as an Aesthetic Tool}

Art, emerged in hospitals in England as early as 1960, and art on walls along a long sterile hallway or sculpture displayed in a bare lobby transformed the hospital into healing environments for patients (Lane, 2006). The use of visual art and light images achieves public satisfaction with their environment, including patient-focused design in healthcare, which improves mood (Ulrich, 1984). Illuminating art murals mounted on the room ceiling over the beds create positive distraction and draw the user's attention away from thinking of being hospitalized and meet patients' satisfaction with their physical setting. Colorful paintings representing clear sky, river and views of sea, or the harbor, and illuminating artwork on the ceiling evoke feelings of joy in hospital rooms and are important features for the interior designer to consider when creating patient-focused room design. Indeed, art on ceiling should become part of hospital room design just like the electrical components of the ceiling (Durto, 2007).

Aesthetically pleasing décor and art can enhance single occupancy user satisfaction and may lead to well-being. Art provides a visual discrepancy and a source of colour, which are linked to happiness. Since art potentially possesses therapeutic benefits, it is important to understand the type of art preferred by patients that contributes to healing (Eisen et al., 2008), and designers should choose the art type that generates positive feelings in the hospital room and not to satisfy their personal taste. Art depicting nature contains considerable detail (Mayer, 1969), and are more desirable than abstract and ambiguous (surreal) art in a hospital setting though abstract art containing images enhances wellbeing, as observed among patients in Liverpool, UK (Cintra, 2001).

\subsection{Brightness and Light as Aesthetic Tools}

An effective use of light is an essential hospital design feature, which when used creatively, can brighten up the hospital room and create a sense of presence and beauty. Brightness is a basic component of aesthetics in hospital rooms that evokes positive feelings. The aesthetic properties of light alters the appearance of the room, and the quality of the visual environment improves patient well-being and recovery as well as staff performance. Historically, hospitals had large windows that allowed natural light to penetrate deep into the building, and solariums were used as healing environments, such that beds were pushed out onto balconies and terraces (Mazuch \& Stephen, 2005). Natural light in hospital rooms, including staff spaces within the building facilitate healing, and is preferred daylight over electric light. With little or no natural light, melatonin tells the body to "log off" and even causes illnesses such as seasonal affective disorder (Mazuch \& Stephen, 2005). With this understanding, the current focus is on using artificial light in a therapeutic fashion and to avoid glare and thermal gain, which applies to natural light as well.

However, artificial lighting layouts particularly, but not exclusively, should be designed to avoid the creation of a stroboscopic lighting effect. In this respect, 
the hospital environment should be well lit and abrupt changes in illumination should be avoided, unless specified as a clinical treatment requirement. Further, window glazing should be designed so as to maximise natural light within the hospital on bright and overcast days alike, while maintaining comfortable light and thermal conditions.

A window is one of the important interior elements in single occupancy and is supported by research, which suggests that windows are related to place attachment. Individuals relate to their physical environments and confer meanings to certain aspects of a place, often resulting in place attachment, which merges three elements; the physical environment, human behavior, and social and/or psychological processes. Patients prefer rooms with windows, but only if they have interesting views, preferably that of nature (Verderber, 1983), rather than an urban environment. Research showed that window views of nature produce higher level of relaxation and lower stress, through a perceptual and cognitive link with external environment, which positively affect the therapeutic process in patients who want to relax and reduce recovery time (Ulrich, 1984). Among other features, texture in hospital room interior brings a richness of material contrast, and plants and flowers, also create a visually appealing environment.

\subsection{Personalization as an Aesthetic Tool}

Personalization of space is the modification of or addition to the interior or exterior environment of a place by the resident to give it meaning. Personal belongings such as memorabilia and family photos, tack board for greeting cards, a favourite chair, quilt, and other things from home, handbag, and gifts increase satisfaction and happiness through cognitive responses and create a place attachment (Malkin, 1992). Users personalize their spaces for expressing themselves, forming emotional ties with their environment, adapt to new places, regulate social interactions, enhance satisfaction, improve aesthetics of a place, to be creative, to reflect their interest, abilities, personalities, lifestyle and values. Studies on hospitalized children found that providing lockable storage and shelves for children to keep their belonging helped them personalize their environment (Acton et al., 1997). Therefore, planning and interior designers should consider personalization when improving room design and creatively employ new techniques to help user personalization in single occupancy room.

\subsection{Ergonomic Attributes of the Framework}

Ergonomics is a relationship between the design of the building environment and its users. A well-designed single occupancy room may uplift user spirit, provide uniqueness and style, enhance individual behavior, provide enjoyment, good feelings, and relaxation. The layout of furniture and equipment can influence user experience and may improve satisfaction because physical comfort is important for user satisfaction. Modern furniture is preferred in hospital rooms, due to the comfort and color options available. The flexibility of layout ar- 
rangement provides support for users who spend a considerable period of time in the hospital room. Allowing users to move furniture and having wheeled furniture will serve this demand. Flexibility in furnishings and mobility and the ability to move furniture around improves user satisfaction. Users face considerable discomfort if furnishings are arranged such that user must turn their bodies to watch the television and therefore musculoskeletal disorders such as carpal tunnel, syndrome, tendonitis, sciatica, herniated discs, and low-back pain can result when the physical environment is not suited to the physical capacity of the person to perform required task (Harris et al., 2002). Physical discomfort may negatively impact users if designers ignore ergonomics features of a hospital room.

Use of the Internet and mobile phones connect the patient to the outside world and make them feel less removed from their lives outside of the hospital. Mary Jo Bitner's (1992) theoretical framework refers to only three conditions ambient, interior, and architecture as important to achieve satisfaction. However, modern living has resulted in the infusion of technology, such as a game console, into healthcare settings to achieve satisfaction, positive behaviour and feeling of excitement, provides positive distraction and entertainment in the hospital room. The use of a game console as an aid to enhance satisfaction in single occupancy hospital room is a novel recommendation introduced in the proposed framework.

\section{Implications for Design of Healthcare Facilities}

The purpose of this study was to integrate design theories for creating healing environments and guiding designers on patient perceptions of hospital interior elements. Four major aspects that influence satisfaction are environmental aesthetics, personalization, technology, mobility and flexibility. Environmental aesthetic components found to be important for user satisfaction include wall and floor color, art, plants, and window views. Personalization helps user to quickly adapt to new environment. Since perception of the aesthetics elements could lead to physiological, emotional and cognitive responses, which may affect patient behavior and satisfaction, the interior designer must consider individual's internal responses during the designing stage. Technology, including the Internet, mobile phone and game consoles provides entertainment and pleasure which may increase satisfaction since the patient will perceive it as a physiological support, which is essential for physical comfort. Planning and creating an appealing single occupancy room are important to increase user satisfaction and improve the quality of healthcare design. Interior designers should address the issue of aesthetics and be aware of the room types preferred to improve the quality of time that users spend in hospital and create appropriately-designed healing spaces.

A novel finding of this study was the use of technology as a physiological support that was deemed an essential requirement for physical comfort. Plan- 
ning and creating an appealing single occupancy room is important for increasing user satisfaction and improving the quality of healthcare. Therefore, hospital room interior designers should be aware of and address the issue of aesthetics of single occupancy rooms to improve patient health and wellness (Gashoot, 2021).

\section{Conclusions}

Evidence that a user's perception of the environment is affected by sociological needs, psychological state, and individual differences is presented within a healthcare setting. By integrating design theories for creating healing environments and guiding designers on patient perceptions of hospital interior elements, we have identified environmental aesthetics, personalization, technology, mobility and flexibility as the major aspects that influence satisfaction. Through a comprehensive understanding of the universal concept of aesthetics and designs concepts, the interior designer is expected to go beyond the functionality of the space, and embrace human senses to achieve user satisfaction by positively influencing mood and behaviour. The word "data" is plural, not singular.

Implication for Practice

Patient satisfaction is no longer restricted to just his/her interaction with hospital staff. It extends to the entire experience, including the design of the hospital room. The theories described in this manuscript and the findings based on empirical evidence can be used to illustrate how design principles can increase patient satisfaction.

\section{Conflicts of Interest}

The author declares no conflicts of interest regarding the publication of this paper.

\section{References}

Acton, L. P., Aoun, A., Dennis, E. et al. (1997). Children's Health Design: Designing for Family-Centered Care. Journal of Healthcare Design, 9, 129-135. https://doi.org/10.1055/s-1997-4460

Allderson, P., Green, S., \& Niggins, J. P. T. (2004). Cochrane Reviewers' Handbook 4.2.1. John Wiley and Sons, Ltd.

Alvarez, L. (2004). The Healing Begins with a Design. The New York Times.

Biley, F. C. (1996). Hospitals: Healing Environments. Elsevier. https://doi.org/10.1016/S1353-6117(96)80087-4

Birren, F. (1979). Human Response to Color and Light. Hospitals, 53, 93-96.

Bitner, M. J. (1992). Servicescapes: The Impact of Physical Surroundings on Customers and Employees. Journal of Marketing, 56, 57-71.

https://doi.org/10.1177/002224299205600205

Cintra, M. (2001). Art in Health Care Buildings: Is Any Art Good Art? In A. Dilani (Ed.), Design \& Health-The Therapeutic Benefits of Design (pp. 303-310). AB Svensk Byggtjänst.

Dijkstra, K., Pieterse, P. M. E., \& Pruyn, A. T. H. (2008). Individual Differences in Reac- 
tions towards Colour in Simulated Healthcare Environments: The Role of Stimulus Screening Ability. Journal of Environmental Psychology, 28, 268-277.

https://doi.org/10.1016/j.jenvp.2008.02.007

Durto, A. (2007). Light Image Therapy in the Health Care Environment. East Tennessee State University.

Eisen, S. L., Ulrich, R. S., Shepley, M. M. et al. (2008). The Stress-Reducing Effects of art in Pediatric Health Care: Art Preferences of Healthy Children and Hospitalized Children. Journal of Child Health Care, 12, 173-190. https://doi.org/10.1177/1367493508092507

Fottler, M. D., Ford, R. C., Roberts, V., et al. (2000). Creating a Healing Environment: The Importance of the Service Setting in the New Consumer-Oriented Healthcare System. Journal of Child Health Care, 45, 91-106. https://doi.org/10.1097/00115514-200003000-00007

Gashoot, M. (2021). Revisiting Healing Environments: Islamic Interior Elements in Hospital Rooms in North Africa. Health Environments Research \& Design Journal. https://doi.org/10.1177/19375867211042350

Harris, P. B., McBride, G., Ross, C. et al. (2002). A Place to Heal: Environmental Sources of Satisfaction among Hospital Patients. Journal of Applied Social Psychology, 32, 1276-1299. https://doi.org/10.1111/j.1559-1816.2002.tb01436.x

Lane, M. R. (2006). Arts in Health Care: A New Paradigm for Holistic Nursing Practice. Journal of Holistic Nursing, 24, 70-75. https://doi.org/10.1177/0898010105282465

Malkin, J. (1992). Hospital Interior Architecture: Creating Healing Environments for Special Patient Populations. Van Nostrand Reinhold.

Mayer, R. A. (1969). Dictionary of Art Terms and Techniques. Crowell Publications.

Mazuch, R., \& Stephen, R. (2005). Creating Healing Environments: Humanistic Architecture and Therapeutic Design. Journal of Public Mental Health, 4, 48-52. https://doi.org/10.1108/17465729200500031

Mehrabian, A., \& Russell, J. A. (1974). An Approach to Environmental Psychology. Massachusetts Institute of Technology.

Mika, B. (2008). Managing the Physical Environment in Service Organization. Lulea University of Technology.

Moore, J. (2000). Designed to Heal: Architecture of Swedish Clinics Is about More than Medicine. Modern Healthcare, 30, 32-34.

Nasar, J. L. (1988). Perception, Cognition and Evaluation of Urban Places. In J. L. Nasar (Ed.), Environmental Aesthetics: Theory, Research and Application (pp. 195-211). Cambridge University Press. https://doi.org/10.1017/CBO9780511571213

Nasar, J. L. (1994). Urban Design Aesthetics: The Evaluative Qualities of Building Exteriors. Environment and Behavior, 26, 377-401. https://doi.org/10.1177/001391659402600305

Palmer, J. B., \& Nash, F. (1997). Taking Shape: Environmental Art in Healthcare. In C. Kaye, \& T. Blee (Eds.), The Arts in Healthcare: A Palette of Possibilities (pp. 101-104). Jessica Kingsley.

Russell, J. A., \& Pratt, G. A. (1980). Description of the Affective Quality Attributed to Environments. Journal of Personality and Social Psychology, 38, 311-322.

https://doi.org/10.1037/0022-3514.38.2.311

Stouffer, J. (2001). Integrating Human Centered Design Principals in Progressive Health Facilities. In A. Dilani (Ed.), Design \& Health-The Therapeutic Benefits of Design (pp. 285-292). Karolinska Institutet. 
Ulrich, R. S. (1984). View through a Window May Influence Recovery from Surgery. Science, 224, 420-421. https://doi.org/10.1126/science.6143402

Ulrich, R. S. (2001). Effects of Healthcare Environmental Design on Medical Outcomes. In A. Dalani (Ed.), Design and Health: The Therapeutic Benefits of Design (pp. 49-59). Swedish Building Council.

Verderber, S. F. (1983). Windowless and Human Behavior in the Hospital Rehabilitation Environment. University of Michigan.

Webster, P. D., \& Johnson, B. H. (1999). Collaborative Design Planning. Institute for Family-Centered Care. 